\title{
In Vitro Bioactivity of Polymer Matrices Reinforced with a Bioactive Glass Phase
}

\author{
Rodrigo L. Oréfice ${ }^{\mathrm{a}^{*}}$, Larry L. Hench ${ }^{\mathrm{b}}$ and Anthony B. Brennan ${ }^{\mathrm{c}}$ \\ ${ }^{a}$ Department of Metallurgical and Materials Engineering, Federal University of Minas Gerais, \\ Rua Espírito Santo, 35 - $2^{\circ}$ andar, 30160-030, Belo Horizonte - MG, Brazil \\ ${ }^{\mathrm{b}}$ Imperial College, Department of Materials Science, London, UK \\ ${ }^{\mathrm{c}}$ University of Florida, Department of Materials Science and Engineering, \\ 32611, Gainesville - FL,USA
}

\begin{abstract}
Nesse trabalho, compósitos de matriz polimérica foram projetados para reproduzir duas importantes características dos vidros bioativos, que são responsáveis por capacitar a tais materiais se ligarem rapidamente ao tecido ósseo: (1) capacidade de prover íons, como os de cálcio e fosfato, ao ambiente vizinho; e (2) possuir uma estrutura de superfície ideal que favoreça uma rápida precipitação heterogênea de hidroxiapatita carbonatada (HCA). Este novo compósito foi preparado através da incorporação de partículas de vidro bioativo numa matriz polimérica. O teste in vitro de bioatividade foi realizado através da introdução das amostras em soluções-tampão, assim como em soluções simuladoras dos fluidos orgânicos. Espectroscopia no infravermelho foi usada para avaliar a cinética de precipitação da HCA. Os resultados mostraram que os compósitos desenvolvidos podem suprir íons em taxas e concentrações comparáveis ou superiores às de vidros bioativos puros. Além disso, a química de superfície dos compósitos foi alterada para reproduzir o tipo de superfície presente em vidros bioativos. Os resultados demonstraram que a bioatividade in vitro de compósitos pode ser ampliada através da modificação química das superfícies do polímero via introdução de grupos alcoxissilanos especiais.
\end{abstract}

Composites that can mimic the in vitro bioactive behavior of bioactive glasses were designed to fulfill two main features of bioactive glasses that are responsible for their high bond-to-bone rates: (1) capability of providing ions such as calcium and phosphate to the nearby environment and (2) ideal surface structure that allows fast heterogeneous precipitation of hydroxy-carbonate-apatite (HCA). The novel composites were prepared by incorporating bioactive glass particles into polymer matrices. The in vitro bioactivity test was performed by introducing samples into a buffered solution as well as into a simulated body fluid solution. FTIR was used to evaluate the kinetics of HCA (hydroxy-carbonate-apatite) precipitation. The results showed that the obtained composites can supply ions, such as silicates and phosphates in rates and concentrations comparable or superior than bulk bioactive glasses. Moreover, the surface chemistry of the composites was altered to mimic the surface of bioactive glasses. It was demonstrated that the in vitro bioactivity of the composites was enhanced by chemically modifying polymer surfaces through the introduction of special alkoxysilane groups.

Keywords: bioactive polymer composites, biomaterials.

\section{Introduction}

The use of synthetic materials as a way to replace damaged tissues has been studied and practiced for a long time. The initial goal was focused on finding an ideal biomaterial that would promote minimum response from the body. This initial idea of "bioinertness" was progressively realized not to be enough for many applications. Moreover, it was ob-

* e-mail: rorefice@demet.ufmg.br served that even the most "inert" material would provoke some type of reaction from the body, expressed by the formation of a thin non-adherent fibrous capsule that would prevent higher levels of interaction between tissue and biomaterial $^{1}$. Nevertheless, fixation of the implant in place is desired in many applications and then adhesion in the biomaterial-tissue system needs to be achieved. Several ways to promote adhesion were then investigated ${ }^{2}$, such as use of plates, pins and screws (mechanical interlock) growth of tissue through a porous biomaterial (biological fixation) fixation 
due to a cementation or polymerization reaction and use of biodegradable pins or sutures.

Another way to promote fixation was demonstrated 3 in the late sixties. In this case, coupling between tissue and material was promoted by an integration process. This integration process is based on the processing of a group of reactions on the material surface that will lead to the formation of a dynamic high-strength interphase. In this interphase, both inorganic and organic species are combined through physical-chemical and biochemical interactions. Materials that promote this type of interaction with living tissues by forming chemical linkages are called bioactive materials. Bioactive glasses and hydroxyapatite are examples of this type of material.

Bond formation between bioactive glasses and living tissues is allowed basically due to the ability of those glasses to corrode when exposed to distilled water or simulated body fluids. When submitted to this type of environment as well as body fluids, a series of reactions starts to develop on the surface of bioactive glasses. These reactions involve: (1) the ion exchange process between the solution and the glass surface, leading to the release of $\mathrm{Na}^{+}, \mathrm{Ca}^{2+}$ and $\mathrm{PO}_{4}{ }^{3-}$ ions and formation of silanol groups ( $\left.\mathrm{SiOH}\right) ;(2)$ release of soluble silica from the glass surface due to the breakage of Si-O-Si bonds; (3) polycondensation of silanol groups and formation of a porous silica rich layer; (4) precipitation of a CaO- $\mathrm{P}_{2} \mathrm{O}_{5}$ rich film on the glass surface; (5) crystallization of a hydroxy-carbonate-apatite (HCA) layer by incorporation of $\mathrm{OH}^{-}$and $\mathrm{CO}_{3}{ }^{2-}$ anions from solution.

In vivo studies revealed that these reactions also occur on the surface of bioactive glass implants ${ }^{3}$. Those studies showed that materials that cannot induce precipitation of a HCA layer in vitro will likely not be able to bind to bone. Moreover, the sequence of events observed in vitro also correlates to in vivo results ${ }^{3}$. Therefore, in vitro experiments that simulate the conditions observed in human bodies can be used to qualitatively study the bond-to-bone ability (bioactivity) of materials. The formation of silica rich and HCA layers is used to define the in vitro bioactive behavior of the material.

A series of six more reactions is observed during a tissue-bioactive material bond formation ${ }^{3}$. They involve interactions between biological species and the HCA-silica rich layers, i. e. the adsorption of biological moieties in the HCA-silica rich layer, attachment of cells, generation of bone matrix and mineralization of bone matrix.

It was shown 4 that the rates of attachment and spreading of certain types of fibroblasts, that are responsible for the formation of the non-adherent fibrous capsule on the surface of "biologically inert" implants were reduced on a bioactive glass surface. On the other hand, cellular activity, including rate of differentiation of osteoblasts, was shown to be enhanced significantly by the bioactive glass surface 5 . In vivo and cell culture studies have shown that the capability of increasing osteoblastic activity is not a characteristic of all bioactive materials. While bioactive glasses can enhance such activity, no great difference was noted between other bioactive materials, such as synthetic hydroxyapatite, and inert materials in relation to this phenomenon 6 . Therefore, the division of bioactive materials in two classes was proposed 2 :

(1) Class A includes bioactive materials, such as bioactive glasses, that not only act as a matrix for bone cell growth (osteoconductive process), but also increase the rate of bone cell proliferation.

(2) Class B includes bioactive materials that are only osteoconductive.

The ability of bioactive glasses to accelerate cell growth has been studied and attributed to the release of soluble silica from these glasses, that would affect intracellular mechanisms 7 .

Class A bioactive materials show experimentally faster rates of in vitro hydroxy-carbonate-apatite layer precipitation (within 20 hours) and higher rates of bond to bone formation in contrast to class B bioactive materials 2 . Class A bioactive materials have also the capability of bonding to soft tissues, while Class B can only bond to bone.

As commented before, most of the bioactive materials are ceramic type materials, and thus they are commonly named bioceramics. Even though the use of bioceramics as implant has spread over the world, the mismatch between the mechanical properties of ceramics in relation to the mechanical properties of natural tissue must be overcome in order to enlarge the number of load bearing applications of bioceramics. Ceramics have typically a higher elastic modulus and a lower fracture toughness than bone. The special mechanical properties of bone and teeth are produced by the combination of a hydroxy-carbonate-apatite phase in a collagen matrix. Therefore, the production of a molecularly tailored composite that can mimic the structure of bone is a potential path to solve the difference in mechanical properties between bioceramics and living tissues.

Polymer composites, which include a bioactive phase, represented by a bioactive glass, glass-ceramic or ceramic introduced into a high mechanical performance polymeric matrix, have potentially the capability of combining bioactive behavior with adequate mechanical properties. These new bioactive composites would then be potentially used in load bearing applications.

In this work, we tested the hypothesis that bioactive polymer composites can be designed to mimic the behavior 
of bioactive glasses regarding the in vitro bioactivity. To accomplish this task, these novel composites will have to furnish ions (such as calcium and phosphate) in rates and concentrations similar to bulk bioactive glasses, and also they will need to have a surface structure that can allow fast deposition of HCA layers. The ultimate goal is to formulate a new biomaterial that would have tailorable bioactive behavior and properties that could fit into the design of a particular biomedical device.

\section{Experimental}

A soda-lime silicate bioactive glass (molar composition: $46.1 \%$ of $\mathrm{SiO}_{2}, 24.4 \%$ of $\mathrm{Na}_{2} \mathrm{O}, 26.9 \%$ of $\mathrm{CaO}$ and $2.6 \%$ of $\mathrm{P}_{2} \mathrm{O}_{5}$ ) was used as the bioactive phase of the composite, being therefore the source of bioactivity and responsible for reinforcing the polymer matrix. The glass was used in a particulate form $(125-106 \mu \mathrm{m})$ and was prepared by ball milling a quenched glass, melted at $1300^{\circ} \mathrm{C}$. Particle sizes were classified with sieves and then measured by light scattering.

Potential candidates for the matrix of the composite are poly(aryl sulfones), due to their high mechanical properties and great stability at body environment ${ }^{8}$. Glass particles were introduced into polymer matrices by using a method that involved the dissolution and reprecipitation of the polymer on particle surfaces. Poly(aryl sulfones) were dissolved in chlorofom $\left(100 \mathrm{~g} / \mathrm{dm}^{3}\right)$. After complete dissolution, glass particles were introduced into the solution and ethanol was added during vigorous stirring. Ethanol is a poor solvent for poly(aryl sulfones) and forces the polymer out of solution. Composites with $40 \%$ volume fraction of particles were prepared, dried at $150^{\circ} \mathrm{C}$ for $24 \mathrm{~h}$ and then hot pressed at $210^{\circ} \mathrm{C}$.

\section{Growth of silicate films on polymer substrates}

In order to promote faster rates of HCA precipitation, silicate species were inserted onto the surfaces of composites. A series of reactions at the surface of poly(aryl sulfones) were processed in order to incorporate silicate species onto it. The heterogeneous modification of poly(aryl sulfones) included the introduction of sulfonic acid groups onto the polymer, through the reaction of the polymer surface with chlorosulfonic acid. The introduced groups were then converted to alkoxysilane groups via reaction with aminopropyl triethoxysilane, or isocyanatopropyl triethoxysilane.

Silicate species were grown on the surface of silanated PAS- $40 \%$ bioactive glass composites, by dipping samples into a sol containing silicate species and calcium nitrate for $15 \mathrm{~min}$, followed by washing with ethanol. A solution containing silicate species was prepared by introducing TMOS (tetramethoxysilane) into a water/ethanol solution $(\mathrm{pH}=$ 1.5 , regulated by adding $\mathrm{HCl}$ and molar ratios between water/ethanol $=0.5$ and water/TMOS $=20$ ). The solution was stirred for 5 min and then $\mathrm{Ca}\left(\mathrm{NO}_{3}\right)_{2}$ was added to the solution. The molar ratio between TMOS and $\mathrm{Ca}\left(\mathrm{NO}_{3}\right)_{2}$ used was calculated to yield a 60/40 ratio between silica and calcium oxide. This silicate film can have ideal characteristics for enhancing the deposition of HCA in body fluids, i.e., high surface area, negative surface charge and high silanol concentration. Furthermore, the presence of calcium ions can also favor a local supersaturation in ions needed for the HCA precipitation.

\section{In vitro test}

Polished composites ( $\mathrm{SiC}$ sand paper \# 600) were submitted to in vitro tests that include the following steps: suspending the sample in simulated body fluids (SBF) or Tris-buffer solution (ratio between sample surface area and solution volume $=0.1 \mathrm{~cm}^{-1}$ ) at $37^{\circ} \mathrm{C}$ for a desired period of time. After that, FTIR diffuse reflection spectroscopy was performed on the sample surface to identify the formation of hydroxy-carbonate-apatite (HCA) layer. The Tris-buffer solution is a water solution buffered at $\mathrm{pH}=7.3$ with 50 $\mathrm{mmol} / \mathrm{dm}^{3}$ of trishydroxymethyl aminomethane and 45 $\mathrm{mmol} / \mathrm{dm}^{3}$ of hydrochloric acid. The SBF was prepared using the following reactants: $\mathrm{NaCl}, \mathrm{NaHCO}_{3}, \mathrm{KCl}$, $\mathrm{K}_{2} \mathrm{HPO}_{4} \cdot 3 \mathrm{H}_{2} \mathrm{O}, \mathrm{MgCl}_{2} \cdot 6 \mathrm{H}_{2} \mathrm{O}, \mathrm{HCl}, \mathrm{CaCl}_{2}, \mathrm{Na}_{2} \mathrm{SO}_{4}$, $\mathrm{NH}_{2} \mathrm{C}\left(\mathrm{CH}_{2} \mathrm{OH}\right)_{3}$ in proportions to yield the concentrations revealed in Table 1. SBF's have ionic concentration close to blood, while Tris-buffer solutions has no inorganic ion other than chlorides. Table 1 compares the ionic concentration of SBF with human blood and Tris-buffer solution 9.

Table 1. Ionic concentrations $\left(\mathrm{mmol} / \mathrm{dm}^{3}\right)$ of SBF (simulated body fluids), human blood plasma and Tris-buffer solution.

\begin{tabular}{lrcc}
\hline Ion & SBF & Tris-buffer & Blood plasma \\
\hline $\mathrm{Na}^{+}$ & 142.0 & 0.0 & 142.0 \\
$\mathrm{~K}^{+}$ & 5.0 & 0.0 & 5.0 \\
$\mathrm{Mg}^{2+}$ & 1.5 & 0.0 & 1.5 \\
$\mathrm{Ca}^{2+}$ & 2.5 & 0.0 & 2.5 \\
$\mathrm{Cl}^{-}$ & 147.8 & 45.0 & 103.0 \\
$\mathrm{HCO}_{3}{ }^{-}$ & 4.2 & 0.0 & 27.0 \\
$\mathrm{HPO}_{4}{ }^{2-}$ & 1.0 & 0.0 & 1.0 \\
$\mathrm{SO}_{4}{ }^{2-}$ & 0.5 & 0.0 & 0.5 \\
\hline
\end{tabular}

FTIRRS (FTIR Reflection Spectroscopy) can give information on the surface chemistry of powders and bulk samples from a depth of 3 to $30 \mu \mathrm{m}$. Thus, the reactions undergone on the surface of bioactive materials can be followed by this technique 10 . FTIR diffuse reflection was performed using a Nicolet 20SXB spectrometer with a triglyceride sulfate detector. A DRIFT (DRIFT: Diffuse 
Reflection FT-IR Spectroscopy) accessory from Tech, Inc. was used to perform diffuse reflectance.

Inductively Coupled Plasma (ICP) was used to analyze the ionic concentration of elements leached from the materials during in vitro test.

\section{Results and Discussion}

\section{Ionic evolution from bioactive composites}

As commented before, the reactivity of bioactive materials, specially bioactive glasses, is related to the capability of these materials to corrode and to furnish ions to the nearby aqueous environment. The rates of surface dissolution and network breakdown can be identified by monitoring the evolution of ions from the material into solution. In order to study the bioactivity of composites, the ionic evolution from these materials was determined and compared to the same process in pure bioactive materials.

Poly(aryl sulfones) samples with $40 \%$ volume fraction of glass and pure bioactive glasses were dipped into a Tris-buffer solution $(\mathrm{pH}=7.3)$ at $37^{\circ} \mathrm{C}$. The samples were kept in solution for the following periods of time: 0,60 and $120 \mathrm{~min}, 6$ and $20 \mathrm{~h}$ and 2, 4 and 7 days. The SA/V (sample surface area per volume of solution) used was $0.1 \mathrm{~cm}^{-1}$. After the designated period of time in solution, the samples were withdrawn and the solution was collected for analysis by ICP. The surface of the collected samples was studied using DRIFT.

In Figures 1 and 2, the solution concentration as a function of time for phosphate and silicate ions, respectively, is displayed for both pure bioactive glasses and composites with $40 \%$ volume fraction of glass. Both ions are present in glass particles and are released due to surface dissolution of the particles. The first and also the most simplistic approach to predict the behavior of a composite composed of bioactive glass particles within a polymer matrix would be to simply apply the "rule of mixture". In this hypothesized case, the behavior of a composite regarding the evolution of ions from the material would only be due to the portion of the surface covered by the glass. In Figure 1, the data calculated using the rule of mixture were also included. These data would be produced by a bioactive composite where only the exposed particles would react. Therefore, by using this simple assumption (rule of mixture), it would be predicted that the kinetics of ionic evolution from a composite with $40 \%$ of its area covered by a bioactive phase would follow the same trend as in a pure bioactive glass but the concentration in solution of leached ions would be $40 \%$ of that due to pure glass. From Figure 1, it is clear that ionic evolution from the composite, although initially lower than from pure glass, is much higher than the rate calculated using the rule of mix- tures. Moreover, after the first $20 \mathrm{~h}$ of test, the concentration of ions released from the composite reaches levels very close to pure bioactive glasses, even though they have a surface only $40 \%$ covered by a truly bioactive phase. This behavior can be explained by the fact that the overall ionic evolution from the composite is actually formed by two different components: release of ions from the exposed particles and release of ions from interfaces between particles and polymer within the composite.

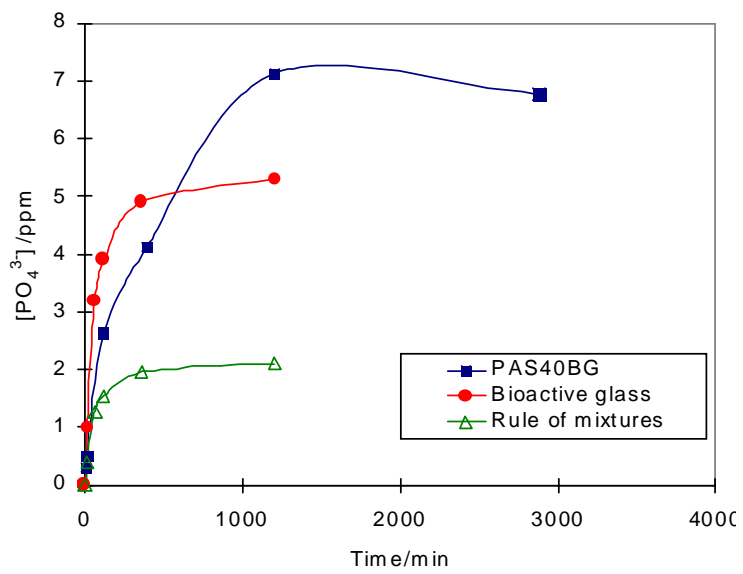

Figure 1. ICP data: ionic evolution of phosphate ions from bioactive glasses and PAS-40\% bioactive glass composites.

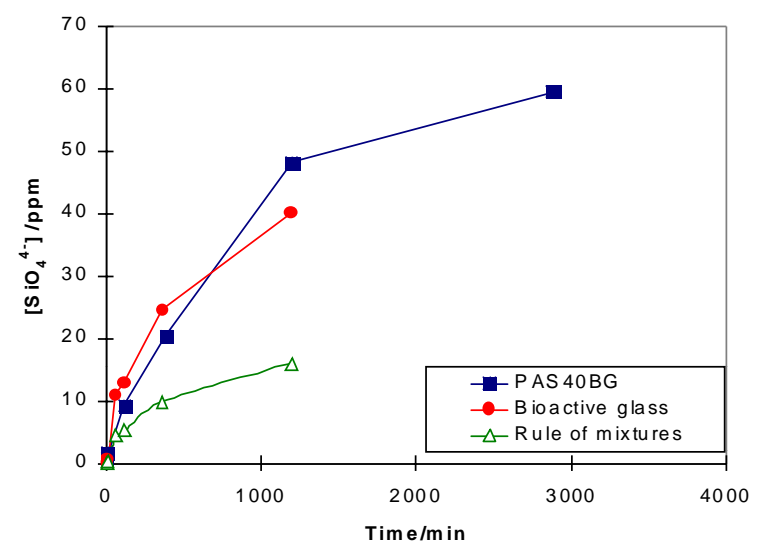

Figure 2. ICP data: ionic evolution of silicate ions from bioactive glasses and PAS-40\% bioactive glass composites.

The usual trend in bioactive materials is that the concentration of ions tends to become stable in solution from the point where the concentration limit of the solution has been reached. A precipitation process may also result in a decrease in the concentration of phosphate ions, since it can lead to the formation of a precipitated layer that can restrict further diffusion of ions from the composite (Figure 1). In terms of phosphate concentration in solution, the ionic concentration in solution for the composite is almost 
1.5 times the concentration in solution for a pure bioactive glass at $20 \mathrm{~h}$ of reaction. After $20 \mathrm{~h}$ of test, the concentration in solution starts to drop as an indication of precipitation of a phosphate rich layer. The higher concentration in solution before precipitation may actually be a result of a higher SA/V (ratio between surface area and volume of solution) than that initially set up for the test (surface area associated with the particles within the composite was not counted in the calculation of the SA/V ratio).

The evolution of silicate ions from bioactive composites in reference to pure bioactive glasses is also exhibited in Figure 2. The trend in this curve is the same as above: higher concentration of silicate ions in solution than expected. The concentration of silicate ions also seems to approach a stable value after $20 \mathrm{~h}$. This concentration, however, is greater than that obtained for pure bioactive glasses as a consequence of the evolution of ions from particles not exposed. The capability of bioactive composites of providing silicate ions to the solution can be very important in defining the type of bioactive behavior developed by the material. As commented before, silicate ions can be responsible for elucidating intracellular mechanisms.

The hypothesis that particles within the composite were participating in the ion exchange process was confirmed by checking the composition of particles on the fractured surface of composites submitted to an in vitro test using electron microprobe (SEM-EDS). Table 2 reveals the results of a semi-quantitative computer routine applied to the EDS results. The composition of pure bioactive glasses is also shown in this table. From these results, it is clear that surface reactions, such as ion exchange, occurred on the surface of particles inside the composite. The sodium concentration, which is the most mobile ion within the glass structure, was reduced and the formation of a silica rich layer was observed. The concentration of calcium was also noticed to decrease when the composition of the reacted layers is compared to bulk bioactive glasses. The concentration of phosphorous was close to the detection limit for EDS and semi-quantitative analysis can produce significant errors. Nevertheless, no variation of the phosphorous concentration was identified for bulk bioactive glasses and reacted layers. The presence of high concentrations of calcium and phosphate ions within the silica rich layer may be related to the deposition of calcium-phosphate precipitates within this layer, as a result of local supersaturation in calcium and phosphate ions in the voids presented in degraded interfaces of composites. Therefore, it was clear that the interface between particles and matrix was acting as a pathway for the infusion of water.

As commented before, the in vitro bioactive behavior of bioactive glasses can be attributed to two major factors:
Table 2. EDS analysis on particles within a poly(aryl sulfones)-40 vol.\% bioactive glass composite submitted to an in vitro test (mol\% concentration).

\begin{tabular}{lcccc}
\hline Samples & $\mathrm{SiO}_{2}$ & $\mathrm{Na}_{2} \mathrm{O}$ & $\mathrm{P}_{2} \mathrm{O}_{5}$ & $\mathrm{CaO}$ \\
\hline Reacted surface particle & 64.2 & 12.3 & 2.7 & 20.8 \\
Bulk bioactive glass & 46.1 & 24.4 & 2.6 & 26.9 \\
\hline
\end{tabular}

evolution of ions from the glass and presence of a very reactive surface area that provides sites for the nucleation of HCA. The results obtained from ICP show that the first factor related to the bioactivity of bioactive glasses (evolution of ions from the material) is closely reproduced by glass-poly(aryl sulfones) composites having $40 \%$ volume of the glass phase. The rate of evolution, as well as the composition of solution after the first $20 \mathrm{~h}$ are higher for composites with $40 \%$ of glass particles when compared with bulk bioactive glasses. Therefore, at least in terms of evolution of ions from the material, composites are performing similarly to bulk bioactive glasses.

Effect of the surface chemistry on the bioactivity of composites

\section{Kinetics of in vitro precipitation of HCA on bioactive polymer composites}

One characteristic of bioactive glasses that enables their in vitro bioactive behavior is the presence of a very reactive surface area, with large number of sites and specific features for the nucleation of a HCA layer. The surface area of bioactive composites has both non-bioactive and bioactive portions. The process of deposition of HCA layers on both non-bioactive and bioactive portions of composites was further investigated by analyzing their behavior when exposed to solutions with neither calcium nor phosphate ions.

Composites (poly(aryl sulfones) 40\% glass) were introduced into Tris-buffer solutions at $\mathrm{pH}=7.3$ and $37^{\circ} \mathrm{C}$. Diffuse reflection FTIR (DRIFT) was then performed on samples withdrawn from the solutions after certain periods of time. Spectra collected after $1 \mathrm{~h}$ (Figure 3-b) and $20 \mathrm{~h}$ (Figure 3-c) are shown in Figure 3. The spectrum collected before the test is also shown to enable comparisons (Figure 3-a). In this spectrum peaks associated with the glass can be seen among others due to the polymer. The characteristic frequencies and assignments of IR absorption are shown in Table 3 for poly(aryl sulfones), bioactive glasses and also hydroxy-carbonate-apatite (HCA). The most important features in the spectra of reacted samples (Figures 3-b and 3-c) are observed in the vibrational frequency range associated with the glass. These regions are mainly located between $1100-900 \mathrm{~cm}^{-1}$ and $500-400 \mathrm{~cm}^{-1}$. After $1 \mathrm{~h}$ of exposure to the buffered solution (Figure 3-b), a peak around $900 \mathrm{~cm}^{-1}$, observed in the 
unreacted composite, had disappeared. This region is associated with the non-bridging oxygen bonds within the glass network. A reduction in this peak is often seen in bioactive glasses due to the progressing of the ion exchange process and polymerization of silanol groups that result in the formation of a silica rich layer. Thus, the result exhibited in Figure 3-b reveals the development of the ion exchange process and formation of a silica-rich layer on the surface of exposed glass particles.

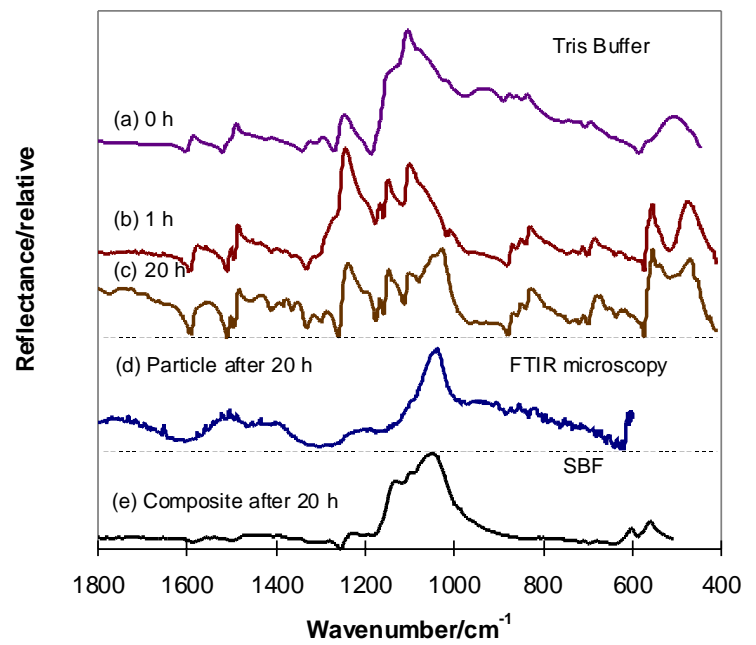

Figure 3. DRIFT (Diffuse Reflection FTIR Spectroscopy) spectra of PAS-40\% glass composites submitted to different in vitro tests: (a) before the test; (b) after $1 \mathrm{~h}$ in a Tris-buffer solution; (c) after $20 \mathrm{~h}$ in a Tris-buffer solution. The spectrum of a particle on the composite surface after $20 \mathrm{~h}$ in a Tris-buffer solution is shown in (d) and was obtained by using FTIR microscopy. In (e), the DRIFT spectrum of the composite after $20 \mathrm{~h}$ in SBF (simulated body fluid) is shown.

Table 3. FTIR frequencies of poly(aryl sulfones), bioactive glasses and hydroxy-carbonate-apatite.

\begin{tabular}{cc}
\hline Wavenumbers $\left(\mathrm{cm}^{-1}\right)$ & Peak Assignment \\
\hline Poly(Aryl Sulfones $):$ reference peaks \\
\hline $3050-2750$ & $v(\mathrm{C}-\mathrm{H})$ \\
$1600-1500$ & $v(\mathrm{C}=\mathrm{C})$ \\
$1376-1300$ & $v_{\text {as }}\left(\mathrm{C}-\mathrm{SO} \mathrm{O}_{2} \mathrm{C}\right)$ \\
1250 & $v(\mathrm{C}-\mathrm{O})$ \\
$1150-1000$ & $v_{\mathrm{s}}(\mathrm{C}-\mathrm{SO}-\mathrm{C})$ \\
$740-690$ & $v(\mathrm{C}-\mathrm{S})$ \\
\hline Bioactive glasses: reference peaks \\
\hline $1100-1000$ & $v(\mathrm{Si}-\mathrm{O}-\mathrm{Si})$ \\
$980-850$ & $\mathrm{v}(\mathrm{Si}-\mathrm{OH})$ \\
$540-415$ & $\mathrm{r}(\mathrm{Si}-\mathrm{O}-\mathrm{Si})$ \\
\hline Hydroxy-carbonate-apatite: & reference peaks \\
\hline $1070-1020$ & $v(\mathrm{P}=\mathrm{O})$ \\
$610-550$ & $\mathrm{r}(\mathrm{P}-\mathrm{O})$ \\
\hline
\end{tabular}

By comparing the spectrum of a sample reacted for $1 \mathrm{~h}$ (Figure 3-b) with that reacted for $20 \mathrm{~h}$ (Figure 3-c), it is possible to observe a shift in the wavenumber of the peak at $1100 \mathrm{~cm}^{-1}$ to lower frequencies. This same trend is observed in pure bioactive glasses due to the formation of HCA layer on the surface of the sample. The new peak seen at $1070 \mathrm{~cm}^{-1}$ is related to the vibrational modes of $\mathrm{P}-\mathrm{O}$ bonds in the HCA layer. Other peaks associated with the HCA are usually located around $600 \mathrm{~cm}^{-1}$ but they cannot be easily seen in the spectrum of the reacted composite because they overlap with polymer peaks. Although not shown in Figure 3, the spectrum of the sample submitted to a 7 daytest in Tris-buffer is very similar to the spectrum exhibited in Figure 3-c, proving that no major changes on the surface of the composites were noted between $20 \mathrm{~h}$ and 7 days. Therefore, the presence of polymer peaks in the spectrum of Figure 3-c suggests that even after $20 \mathrm{~h}$ and 7 days in Tris-buffer solution, a HCA layer is not present on the whole surface of the composite, but possibly only on the glass particles. The deposition of the HCA layer only on the surface of the exposed glass particles was confirmed by FTIR microscopy (Figure 3-d). In this case, an optical microscope was used to identify microscopic features (particles) and to focus the IR beam on them. The spectrum of glass particles on the surface of the composite after $20 \mathrm{~h}$ in Tris-buffer is shown in Figure 3-d. The peak around 1070 $\mathrm{cm}^{-1}$ clearly demonstrates the presence of a HCA layer on the surface of the glass particles. Otherwise, no HCA was observed in the area covered by the polymer in the composite surface even in 7 days.

In Figure 3-e, the DRIFT spectrum of a composite with $40 \%$ volume fraction of glass, submitted to an in vitro test in SBF (solution that is rich in calcium and phosphate ions) instead of tris-buffer solution*, is shown. The peaks shown in this figure (peaks around 1070, 600 and $550 \mathrm{~cm}^{-1}$ ) are typical HCA infrared peaks. Moreover, peaks due to the polymer and glass are barely seen in this spectrum, denoting that the characteristic signals of those materials were reduced by the presence of a HCA layer covering the whole surface of the composite. FTIR microscopy and SEM images were used to prove that a HCA layer was actually covering the entire surface of the composite reacted for $20 \mathrm{~h}$ in SBF. Figure 4 shows a SEM (Scanning Electron Microscopy) micrograph of the surface of a composite with $40 \%$ volume fraction of particles after $20 \mathrm{~h}$ in SBF. This micrograph revels the characteristic acicular texture of a HCA layer covering the whole surface.

Figures 3-c to 3-e allow an important conclusion to be made, that is related to the behavior of the composites in vitro when immersed in Tris-buffer compared to composites immersed in a SBF solution. After $20 \mathrm{~h}$ in SBF, a fully developed HCA layer that covers the whole composite

*SBF has an ionic concentration close to blood while in Tris-buffer there are no inorganic ions, but $\mathrm{Cl}^{-}$. 


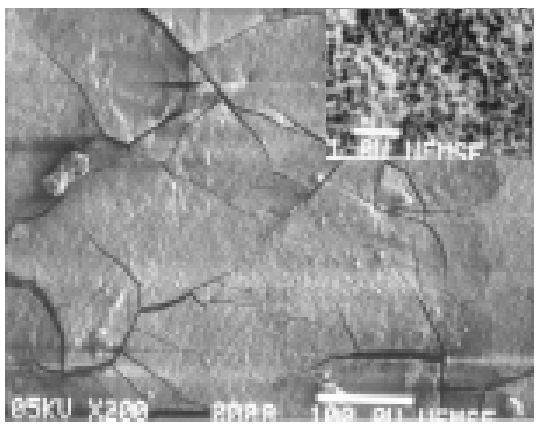

Figure 4. SEM micrograph of the surface of a PAS- $40 \%$ glass composites after $20 \mathrm{~h}$ in a SBF solution. On the top: higher magnification of the same surface to reveal HCA texture.

surface can be noted, while only the particles are covered with HCA after the first $20 \mathrm{~h}$ in Tris-buffer. Since SBF is a metastable solution with respect to the precipitation of HCA, the solubility limit for a heterogeneous precipitation of HCA or even homogeneous precipitation can be easily reached. Thus, calcium and phosphate ions migrating from exposed and internal glass particles of the composite can cause a local solution saturation that would force the heterogeneous precipitation of HCA on exposed glass particles and also homogeneous HCA precipitation on the rest of the composite surface. In Tris-buffer, ions migrating from particles of the composite can locally saturate the solution near the surface. However, the levels of saturation reached are not enough to induce homogeneous precipitation of HCA and only heterogeneous precipitation on the surface of exposed glass particles will occur within short periods of time (up to seven days for PAS-40 vol.\% glass composite).

\section{Growth of silicate films on polymer substrates as a method to enhance bioactivity of polymer composites}

As discussed before, PAS-40 vol.\% bioactive glass composites can provide the ionic evolution typical of bioactive glasses but the percent of the surface covered by the polymer does not have the characteristics that can lead to heterogeneous precipitation of HCA (such as silanol groups, high surface area and negative surface charge). As a consequence of this fact, HCA deposition only occurs on the surface of exposed particles in 7 days, for bioactive composites tested in solutions with low concentration of calcium and phosphate ions.

In this work, the hypothesis that surfaces of bioactive composites can also be designed to promote enhanced rates of HCA precipitation was tested. This improved bioactive composite would then possibly be classified as "Type A" bioactive material ${ }^{2}$. The surface modification of the composite consisted on the incorporation alkoxysilane species on the polymeric fraction of the surface of a bioactive composite.
In vitro test on silicated poly(aryl sulfones)-bioactive glass composites

Surface silicated poly(aryl sulfones)-40 vol. $\%$ bioactive glass composites were submitted to a $20 \mathrm{~h}$ in vitro test in Tris-buffer at $\mathrm{pH}$ 7.3. A DRIFT spectrum of a silicated composite before the in vitro test is reproduced in Figure 5-b, while the spectrum of a non-modified PAS-glass composite is exhibited in Figure 5-a . Siloxane peaks at 1100$1000 \mathrm{~cm}^{-1}$ can be seen in Figure 5-b, while polymer peaks were not present, indicating the presence of a thick silicate film covering the majority of the composite surface. Peaks between $700-640 \mathrm{~cm}^{-1}$ are usually assigned to hydrates and can be due to the presence of calcium hydrates. It was then demonstrated the success of the procedure developed to grow silicate species on poly(aryl sulfones) surfaces.

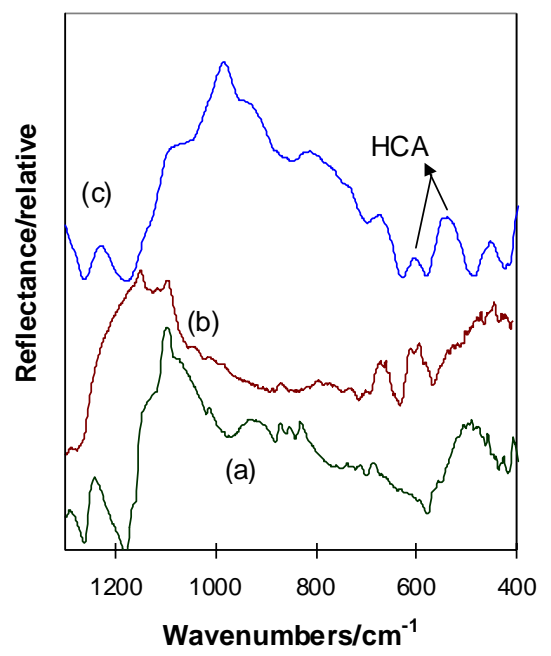

Figure 5. DRIFT spectra of a series of PAS-40\% glass composites with modified surfaces: (a) untreated surface before in vitro test; (b) silicated surface before in vitro test; (c) silicated surface after $20 \mathrm{~h}$ in a Tris-buffer solution.

The DRIFT spectrum of the silicated composite after 20 $h$ in Tris-buffer is revealed in Figure 5-c. The peaks due to the deposition of a thick HCA layer covering the whole composite surface were observed in this spectrum (600-550 $\mathrm{cm}^{-1}$ ), while no polymer peaks are detectable.

Since an untreated poly(aryl sulfones)-40\% bioactive glass composite does not develop a HCA layer covering the whole surface of the sample within 7 days, the growth of silicate species from the poly(aryl sulfones) fraction of the composite surface shifted the onset of HCA precipitation to shorter times. This new composite with silicated surfaces is then following the in vitro behavior of class A bioactive material, and therefore can potentially bend to both soft and hard tissues as well as induce intracellular mechanisms such as to enhance osteoblastic activity. 


\section{Conclusion}

Summarizing the overall phenomenon of in vitro bioactivity of the investigated composites, it is possible to say that composites with $40 \%$ volume fraction of glass behave similarly to highly bioactive glasses in terms of ionic evolution from the material. Extensive and fast release of silicate and phosphate ions from materials when exposed to body fluids are particular characteristics of highly bioactive materials. The similar or higher rates of ionic evolution from composites, when compared to bulk bioactive glasses, were explained by the fact that particles within the composite are participating in the overall dissolution process.

It was noted that precipitation of HCA on the whole composite surface, within periods of time similar to bioactive glasses, can occur if the solution used is already saturated in calcium and phosphate. Otherwise, if the solution used for the in vitro test is not saturated, only precipitation at the exposed glass surfaces occurs in seven days. In this work, a contribution of both (1) heterogeneous nucleation of HCA induced on the exposed glass particles, and also (2) homogeneous HCA precipitation induced by oversaturation of the solution in calcium and phosphate ions was proposed to explain the deposition of a HCA layer on the entire surface of composites when exposed to SBF.

In order to provide structural features to the surface of bioactive composites similar to the ones present on bioactive glasses, silicate species were grown on the partial surface of particulate composites covered by the polymer. Poly(aryl surfones) at the surface of composites was heterogeneously modified by attaching alkoxysilane groups on its backbone. Silicate species were then grown on this portion of the composite surface by using the sol-gel technique.

Composites composed of PAS- $40 \%$ volume fraction of bioactive glasses having highly silicated surfaces were able to develop a thick and uniform layer of hydroxy-carbonateapatite throughout the composite surface within $20 \mathrm{~h}$, when tested in a Tris-buffer solution. As demonstrated earlier, this same composite but having natural surfaces did not have their surfaces fully covered with HCA within seven days at the same test conditions. Therefore, bioactive polymer composites with modified surfaces, such as the one investigated in this work, can potentially be classified as Class A Bioactive Materials, since they can fulfill the in vitro requirements previously defined for this classification, such as: high rates of calcium, phosphate and silicate ions evolution from the material similar or higher than the ones reported for bioactive materials Class A; capability of promoting fast deposition of HCA layers when exposed to solutions with metastable concentrations of calcium and phosphate ions; capability of promoting fast deposition of HCA layers when exposed to solutions with low concentrations of calcium and phosphate ions. A type A bioactive material ${ }^{2}$ can bind to both soft and hard tissues as well as induce intracellular mechanisms such as to enhance osteoblastic activity.

\section{Acknowledgment}

The authors gratefully acknowledge the financial assistance of $\mathrm{CNPq}$ (Conselho Nacional de Desenvolvimento Científico e Tecnológico) of the Brazilian Government.

\section{References}

1. Hench, L. L.; Wilson, J. An Introduction to Bioceramics, World Scientific, 1993.

2. Hench, L. L.; West, J. K. Life Chem. Report. 1996, $13,187$.

3. Hench, L. L.J. Am. Ceram. Soc. 1991, 74, 1487.

4. Seitz, L.; Noonan, K. D.; Hench, L. L.; Noonan, N. E.J. Biomed Mat. Res. 1982, 16, 195.

5. Vrouwenvelder, W. C.; de Groot, G. J. Biomed. Mater. Res. 1993, 27, 465.

6. Oonishi, H.; Kushitani, S.; Yasukawa, E.; Kawakami, H.; Nakata, A.; Koh, S.; Hench, L.L; Wilson, J.; Tsuji, E.; Sugihara, T. Clinical Orthopaedics, 1995, 21, 321.

7. Keeting, P. E.; Ousler, M. J.; Wiegand, K. E.; Bonde, S. K.; Spelsberg, T. C.; Riggs, B. L. Zeolite J. Bone and Mineral Res. 1992, 71, 1281.

8. Sepctor, M. Non-cemented Total Hip Arthroplasty, Raven Press, 1988, Chapter 13, 227.

9. Filgueiras, M. R.; LaTorre, G.; Hench, L. L. J. Biomed. Mat. Res. 1993, 27, 445.

10. LaTorre, G.; Hench, L. L. Characterization Methods for the Solid Solution Interface in Ceramic Systems, American Ceramic Soc., 1993. 